\title{
Assessment of microleakage of class $V$ restored by resin composite and resin-modified glass ionomer and pit and fissure resin-based sealants following Er:YAG laser conditioning and acid etching: in vitro study
}

This article was published in the following Dove Press journal: Clinical, Cosmetic and Investigational Dentistry

\section{Emilie Luong' \\ Amir Shayegan²}

'Department of Children and Adult Operative Dentistry, César de Paepe Hospital, Free University of Brussels, Bruxelles, Belgium; ' 2 Department of Children and Adult Operative Dentistry, Children's Hospital of Queen Fabiola, Free University of Brussels, Bruxelles, Belgium
Correspondence: Emilie Luong Department of Children and Adult Operative Dentistry, César de Paepe Hospital, Free University of Brussels, 13 rue des Alexiens, 1000 Bruxelles, Belgium Tel +32 25067 III

Email luong.emilie87@gmail.com

\begin{abstract}
Aim: The aim of this study was to make a comparison between microleakage of conventionally restored class $\mathrm{V}$ cavities using acid etchant and the ones conditioned by erbium-doped yttrium aluminum garnet (Er:YAG) laser, and also to assess and compare the effectiveness of enamel surface treatments of occlusal pits and fissures by acid etching and conditioned by Er:YAG laser-etch. Materials and methods: Seventy-two extracted third molars were used in this study. The samples were divided into two major groups: class V cavities and pit and fissure sealants. Each subgroup was divided into conventional acid etching, Er:YAG laser conditioning and conventional acid etching, and combination with Er:YAG laser conditioning $(n=12)$. The teeth were placed in $2 \%$ methylene blue dye solution, were sectioned, and were evaluated according to the dye penetration criteria. Two samples per subgroup were chosen for scanning electron microscopic (SEM) analysis.
\end{abstract}

Results: There was a significant difference between occlusal and cervical margin groups. Laser conventional composite cementum group showed more microleakage values compared to other groups. There was no significant difference between occlusal margin groups. However, there was a significant difference between cervical margin groups in terms of microleakage. In sealant groups, there was a significant difference between laser and conventional with/without laser treatment groups in terms of microleakage.

Conclusion: Based on the results reported in this study, it can be concluded that the application of the Er:YAG laser beneath the resin composite, the resin-modified glass ionomers (GIs), and the fissure sealant placement may be an alternative enamel and dentin etching method to acid etching.

Keywords: Er:YAG laser, microleakage, etching

\section{Introduction}

The principal aim of restorative dentistry was to restore the tooth to its form and function. The longevity of the restoration is dependent upon many factors such as the capability to adapt well to a cavity when it is properly placed and good adhesion to the cavity walls. Failure of restorative materials to completely bond to enamel and dentin, causing microleakage, is a concern in restorative dentistry. ${ }^{1}$ Treatment of dental tissues prior to adhesive restorative procedures is an extremely important step in the bonding protocol and determines the clinical success of restorations. Retention of dental resin materials is enhanced greatly by pretreatment of the enamel surfaces 
with certain inorganic acids or chelators. Phosphoric acid was first proposed by Buonocore and was used in dentistry as an etching agent for enamel and later for dentin., ${ }^{2,3}$

The interaction of the etching agents with dentin is limited by the buffering effect of hydroxyapatite and other dentin components. The acidic agents remove the smear layer and the superficial part of the dentin, open the dentin tubules, demineralize the dentin surface, and increase the microporosity of the intertubular dentin. ${ }^{4}$ Penetration of the acids occurs primarily along the tubules. Bonding to dentin is thought to basically rely on a micromechanical entanglement of hydrophilic resins into this demineralized microporous dentin, thus forming a reticular intertwined hybrid tissue composed of collagen, residual mineral particles, and resin. ${ }^{5}$

The composite bond strength to dentin is much less than that compared to enamel, mainly due to the heterogeneous nature of dentin (hydroxyapatite and collagen) and the higher water content of dentin compared to enamel and the hydrophobic nature of these restorative materials. Polymerization shrinkage causes cracks at the tooth-restoration interface increasing the risk of microleakage and secondary caries. ${ }^{6}$

Glass ionomer (GI) cement presented some properties and advantages over other dental materials such as capacity to bond to the tooth structure, fluoride release, good marginal sealing, little microleakage, and biocompatibility. ${ }^{7,8}$

Restoring cervical lesions with resin composites has been a problem, particularly where no enamel is present for bonding to the gingival margin. The cementum outer layer is hypomineralized and hyperorganic, which does not provide microretention for the adhesive materials even after acid etching. ${ }^{9}$

Occlusal pits and fissures are particularly vulnerable to caries and currently account for $\sim 90 \%$ of all caries-affected tooth surfaces. ${ }^{10}$ Special preventive methods are therefore needed if further caries reduction is to be obtained. Application of fissure sealants and fluoride varnishes are two preventive procedures developed since 1970s for dental caries. ${ }^{11}$ The success of fissure sealants principally depends upon the quality of adhesion between the sealant and enamel, which determines their ongoing resistance to the microleakage of saliva and microorganisms at the interface. ${ }^{12-14}$ The adhesion and retention of the sealant are essentially derived from micromechanical interlocking, as very little chemical interaction exists between the resin and the enamel.

Recently, various enamel and dentin treatment procedures are still under discussion for the optimization of fissure sealant penetration and good adhesion to the cavity walls.
In recent years, there has been a significant progress in the use of lasers in dentistry including erbium-doped yttrium aluminum garnet laser (Er:YAG laser). Since the first publication dealing with Er:YAG laser application in dentistry in 1989, several articles concerning the use of Er:YAG laser have been published. ${ }^{15}$ Er:YAG laser is highly promising for use in numerous dental procedures, including the caries treatment, preparation of dental hard tissues (enamel, dentin, and cementum), prevention and treatment of dentin hypersensitivity, and the periodontal treatment. ${ }^{16-19}$ It also proves to be useful in endodontic and soft tissue excision, incision and ablation, and decontamination of root and implant surfaces. ${ }^{20}$

As a possible alternative to acid conditioning, the use of laser therapy has recently shown a promising front. ${ }^{21}$ The laser effects on dental tissues consist of thermo-mechanical wear and evaporation of water content. Laser etching is done through a process of continuous vaporization and micro explosions of water entrapped in the hydroxyapatite matrix. This causes expansion and disposal of organic and inorganic tissue contents and ultimately a surface with open dentinal tubules without smear layer.

The aim of this study was to make a comparison between microleakage of conventionally restored class $\mathrm{V}$ cavities using acid etchant and the ones conditioned by Er:YAG laser as well as to assess and compare the effectiveness of enamel surface treatments of occlusal pits and fissures by acid etching and which are conditioned by Er:YAG laser-etch.

\section{Materials and methods}

The procedure to obtain healthy extracted teeth was approved by the Ethics Committee of the Children's Hospital of Queen Fabiola, Free University of Brussels (CEH 24/16). Patients/ parents provided the written informed consent. Seventy-two freshly extracted non-carious human third molars free from cracks were collected and placed in physiologic saline solution until cavity preparation. The distribution of treated teeth is listed in Table 1.

\section{Class V}

\section{Cavity preparation}

After surface debridement with a hand-scaling instrument and cleaning with a rubber cup and slurry of pumice, a conventional class $\mathrm{V}$ cavity ( $\sim \mathrm{mm}$ wide, $2 \mathrm{~mm}$ high, and 2 $\mathrm{mm}$ deep) was prepared on the buccal and lingual surfaces of 60 teeth, using a straight diamond bur (Intensiv ISO 012 FG 8714/6) under constant air-water spray. The coronal margins were located $1 \mathrm{~mm}$ in enamel and the cervical margins were 


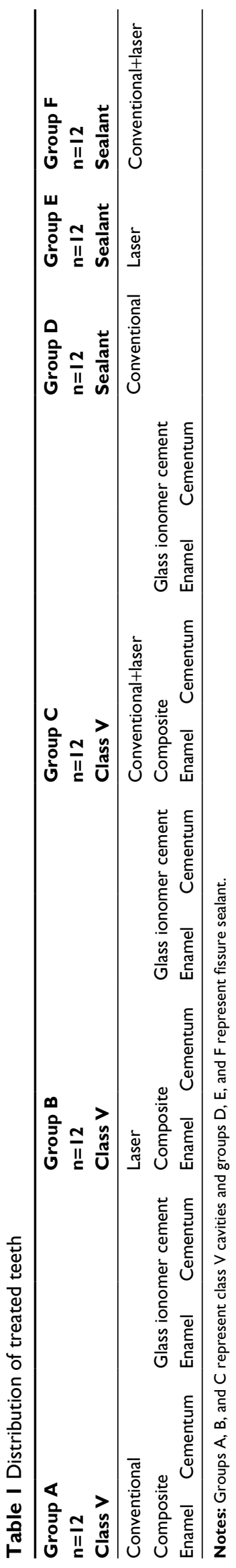

located $1 \mathrm{~mm}$ in cementum. The samples were divided into three experimental groups $(n=12)$.

\section{Group A}

Buccal cavity (conventional enamel composite [CEC] and conventional cementum composite [CCC])

After cavity preparation, the enamel, dentin, and cement

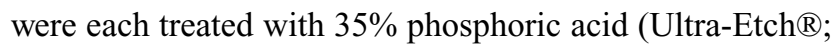
Ultradent Products, Inc., South Jordan, UT, USA) for 10 to 20 seconds. The cavity was rinsed thoroughly with water and dried with a mild oil-free air stream. A total-etch adhesive system (Optibond ${ }^{\mathrm{TM}}$ FL; Kerr Corp., Orange, CA, USA) was applied to all cavities according to the manufacturer's instructions. Primer was applied to the entire cavity wall and was left to dry for 20 seconds. After conditioning the tooth surface for 20 seconds, the cavity was exposed to a mild oil-free air stream. Following the primer procedures, bond was applied to the entire surface of the cavity, obtaining the bond film, as uniform as possible, by using a gentle oil-free air stream. The tooth surfaces were polymerized with an EliparTM S10 LED curing light (3M ESPE, St. Paul, MN, USA) for 20 seconds. The composite resin (Filtek ${ }^{\mathrm{TM}}$ extreme XTE; 3M ESPE, Seefeld, Germany) was inserted in two increments and light cured for 40 seconds. The restorations were then polished with Sof-Lex (3M ESPE, USA).

Lingual cavity (conventional enamel glass ionomer cement [CEGIC] and conventional cementum glass ionomer cement [CCGIC])

After cavity preparation, the cavity was treated with a mild polyacrylic acid solution 10\% (Dentin Conditioner ${ }^{\mathrm{TM}}$; GC Corporation, Tokyo, Japan) by using a microbrush applicator. After conditioning the tooth surface for 20 seconds, the cavity was exposed to a mild oil-free air stream. The GI resin (GC Fuji II LC Improved; GC Corporation) was inserted in two increments and light cured for 20 seconds. The restored surfaces were coated with GC Fuji varnish (GC Corporation).

Group B

Buccal (laser enamel composite [LEC] and laser cementum composite [LCC]) and lingual (laser enamel glass ionomer cement $[\mathrm{LEGIC]}$ and laser cementum glass ionomer cement $[\mathrm{LCGIC]}$ ) cavities

After cavity preparation, no acid treatment was used. The cavities were treated (etched) with Er:YAG laser (Fotona, Ljubljana, Slovenia) in Quantum Square Pulse (QPS) mode $(1.2 \mathrm{~W}, 10 \mathrm{~Hz}$, wavelength $2.94 \mu \mathrm{m})$. Then the teeth were sealed as described in group A. 


\section{Group C}

Buccal (conventional laser enamel composite [CLEC] and conventional laser cementum composite [CLCC]) and lingual (conventional laser enamel glass ionomer cement [CLEGIC] and conventional laser cementum glass ionomer cement [CLCGIC]) cavities

An acid agent as described in group A treated the cavities. After conditioning, the tooth cavities were treated (etched) with Er:YAG laser. Then the teeth were sealed as described in group $\mathrm{A}$.

\section{Fissure sealant}

After surface debridement with a hand-scaling instrument and cleaning with a rubber cup and slurry of pumice, the teeth were thoroughly washed and dried with a mild oil-free air stream.

\section{Group D}

\section{Conventional sealant (CS)}

The occlusal pit and fissures were etched for 20 seconds and rinsed for 15 seconds. Fissure sealant (Clinpro ${ }^{\mathrm{TM}}$; $3 \mathrm{M}$ ESPE, Germany) was then applied and light cured for 20 seconds according to the manufacturer's instructions.

\section{Group E}

\section{Laser-etched sealant (LS)}

No acid treatment was used. The occlusal pit and fissures were treated (etched) with Er:YAG laser (Fotona) in QPS mode $(1.2 \mathrm{~W}, 10 \mathrm{~Hz}$, wavelength $2.94 \mu \mathrm{m})$. Then they were sealed as described in group $\mathrm{D}$.

\section{Group F}

\section{Conventional laser-etched sealant (CLS)}

The occlusal pit and fissures were etched for 20 seconds, rinsed for 15 seconds, and were then treated (etched) with Er:YAG laser. Fissure sealant was applied as described in group D.

After sealing, the samples were placed in distilled water at $37^{\circ} \mathrm{C}$ and then thermocycled 1,000 times between $5^{\circ} \mathrm{C}$ and $55^{\circ} \mathrm{C}$ with a transfer time of 10 seconds and a dwell time of 30 seconds.

\section{Dye penetration}

Sixty teeth (10 per group) were covered with two layers of nail varnish till $1 \mathrm{~mm}$ around the restorations. The teeth were placed in $2 \%$ methylene blue dye solution for 24 hours and rinsed under flowing tap water to remove excess dye. The samples were sectioned in the buccolingual direction by using a water-cooled diamond saw (Leitz 1600 saw microtome; Ernst Leitz Wetzlar GmbH, Wetzlar, Germany) to obtain 4-5 slices for the groups A, B, and C and 7-8 slices for the groups D, E, and F. All sections were viewed under a stereomicroscope (Leica EZ4W; Leica Microsystems CMS $\mathrm{GmbH}$, Wetzlar, Germany) and were evaluated according to the following criteria:

1. No evidence of dye penetration

2. Dye penetration along the occlusal/gingival wall to less than half of the cavity depth

3. Dye penetration along the occlusal/gingival wall to more than half of the cavity depth, but not extending on to the axial wall

4. Dye penetration along the occlusal/gingival wall to the full cavity depth, but extending onto the axial wall

The data collected were statistically analyzed by using the one-way ANOVA and Tukey's multiple comparison test. The level of significance was set at $P<0.05$. The statistical analyses were performed by using the software "GraphPad Prism" version 7 (GraphPad Software, Inc., La Jolla, CA, USA).

\section{Scanning electron microscopic (SEM) analysis}

For SEM evaluation, two representative specimens from each subgroup were taken. The teeth were sectioned in the buccolingual direction, and the specimens were subjected to dehydration in acetone solution for 2 minutes. The specimens were mounted on aluminum stubs, dried in vacuum, and then coated with $20 \mu \mathrm{m}$ platinum. The samples were examined under SEM (Quanta 200; FEI Company, Hillsboro, OR, USA). Micrographs were taken to observe the quality of bonding between the restorations and dental hard tissue (Figures 1-4).

\section{Results \\ Dye penetration Class V}

The data collected were shown in Tables 2 and 3. There was a significant difference between occlusal and cervical margin groups $(P<0.0001)$. Laser conventional cementum composite (LCCC) group showed more microleakage values compared to other groups.

\section{Occlusal margin}

There was no significant difference between groups. Nevertheless, CEC group presented more microleakage values (Figure 5). 


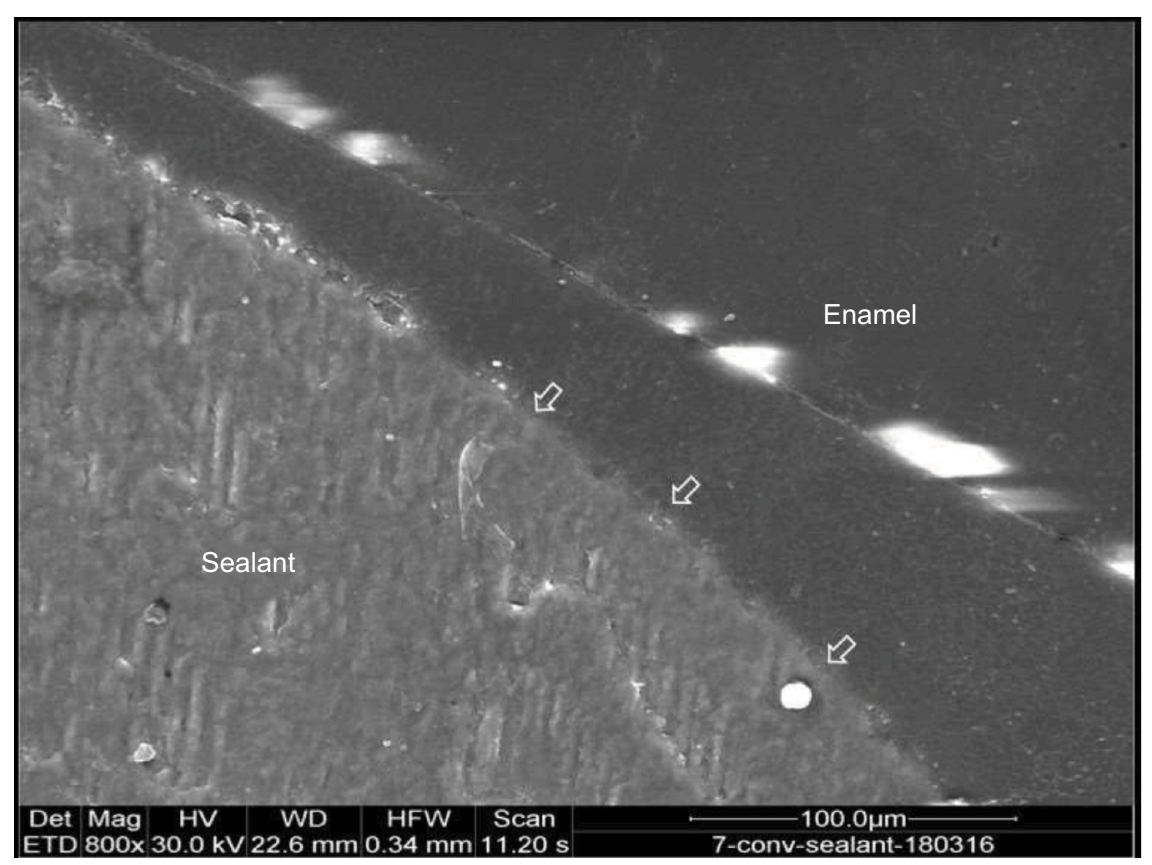

Figure I Acid etching sealant: interface between sealant material and enamel (arrows). SEM $\times 800$.

Abbreviation: SEM, scanning electron microscope; det, detector; ETD, Everhart-Thornley Detector; Mag, magnification; HV, high voltage; WD, working distance; HFW, horizontal field width.

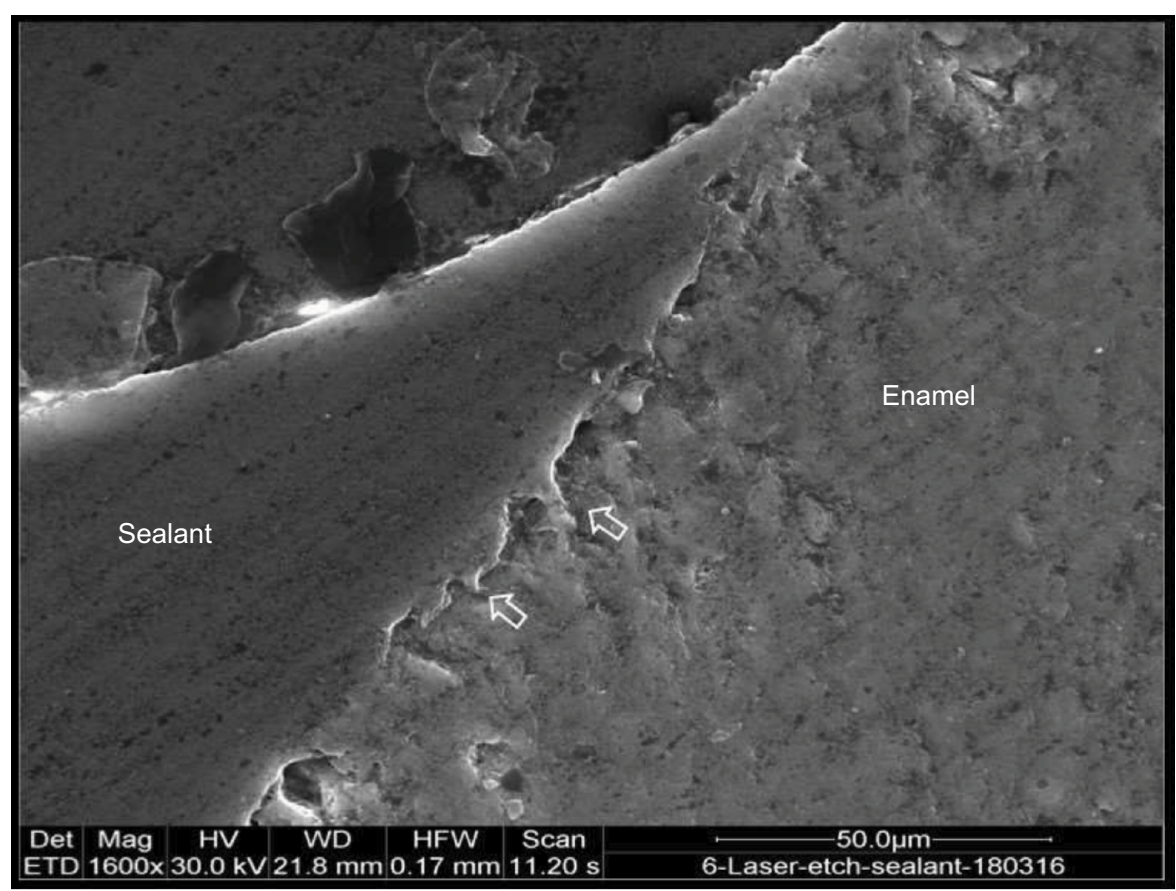

Figure 2 Laser etching sealant: created microretention by Er:YAG laser (arrows). SEM $\times 1,600$.

Abbreviations: Er:YAG, erbium-doped yttrium aluminum garnet; SEM, scanning electron microscope.

\section{Cervical margin}

There was a significant difference between the comparing groups LCCC, LCGIC, laser conventional cementum glass ionomer cement (LCCGIC) $(P<0.0002)$, CCGIC $(P<0.001)$, and CCC $(P<0.05)$ in terms of microleakage (Figure 6).

\section{Fissure sealant}

The data collected are shown in Table 4 and Figure 7. Oneway ANOVA indicated significant differences between the groups $(P<0.05)$. There was a significant difference between LS and CLS groups with CS group in terms of microleakage $(P<0.05)$. 


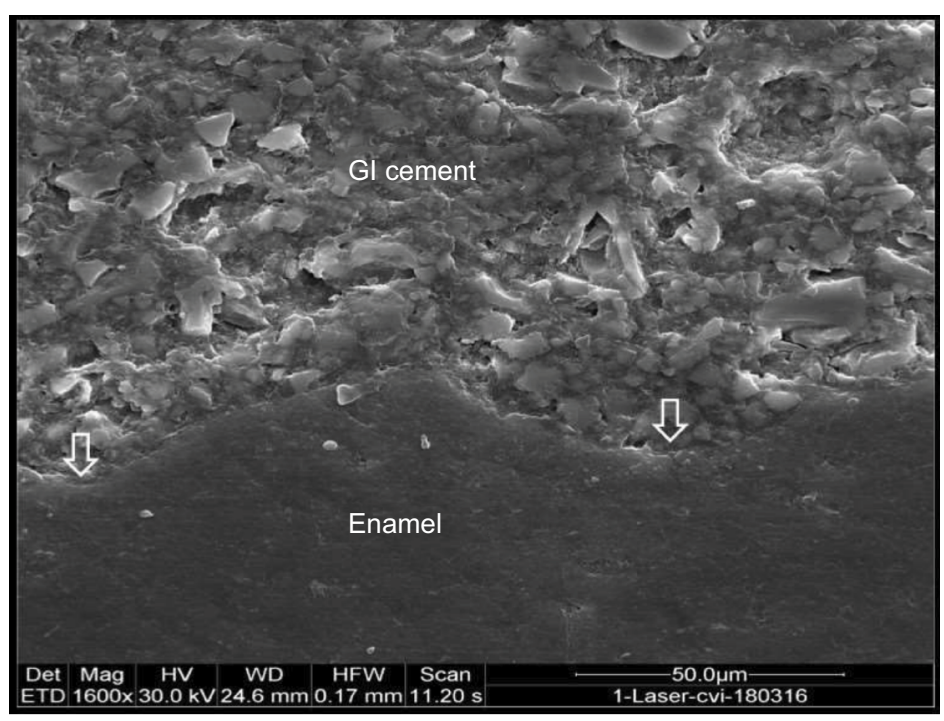

Figure 3 Laser etching GI cement: created microretention by Er:YAG laser (arrows). SEM $\times 1,600$.

Abbreviations: GI, glass ionomer; Er:YAG, erbium-doped yttrium aluminum garnet; SEM, scanning electron microscope.

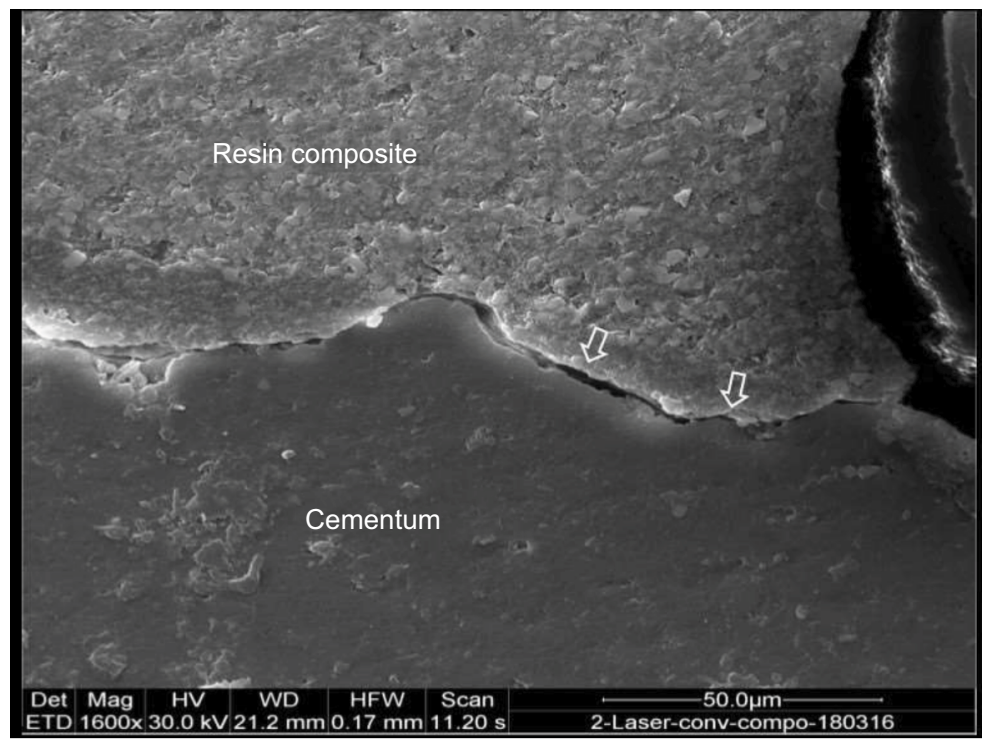

Figure 4 Acid and laser etching cervical margin: microleakage between resin composite and cementum (arrows). SEM $\times 1,600$. Abbreviation: SEM, scanning electron microscope.

Table 2 Grading of dye penetration of occlusal margin

\begin{tabular}{llllll}
\hline CEC & CEGIC & LEC & LEGIC & LCEC & LCEGIC \\
\hline 0 & 0 & 0 & 0 & 0 & 0 \\
0 & 0 & 0 & 0 & 0 & 0 \\
0 & 0 & 0 & 0 & 0 & 0 \\
0 & 0 & 0 & 0 & 0 & 0 \\
0 & 0 & 0 & 0 & 0 & 0 \\
0 & 0 & 0 & 0 & 0 & 0 \\
2 & 0 & 0 & 0 & 0 & 0 \\
0 & 0 & 0 & 0 & 0 & 0 \\
0 & 0 & 0 & 0 & 0 & 0 \\
1 & 0 & 0 & 0 & 0 & 0 \\
\hline
\end{tabular}

Abbreviations: CEC, conventional enamel composite; CEGIC, conventional enamel glass ionomer cement; LEC, laser enamel composite; LEGIC, laser enamel glass ionomer cement; LCEC, laser conventional enamel composite; LCEGIC, laser conventional enamel glass ionomer cement.
Table 3 Grading of dye penetration of cervical margin

\begin{tabular}{llllll}
\hline CCC* & CCGIC & LCC** & LCGIC & LCCC*** & LCCGIC \\
\hline 0 & 0 & 0 & 1 & 0 & 0 \\
1 & 0 & 0 & 0 & 4 & 0 \\
1 & 0 & 0 & 0 & 3 & 0 \\
1 & 0 & 0 & 0 & 3 & 0 \\
1 & 0 & 3 & 0 & 0 & 0 \\
0 & 2 & 3 & 0 & 4 & 0 \\
0 & 0 & 0 & 0 & 4 & 0 \\
0 & 2 & 4 & 0 & 4 & 0 \\
2 & 0 & 0 & 0 & 4 & 0 \\
3 & 0 & 3 & 0 & 0 & 1 \\
\hline
\end{tabular}

Note: ***Very highly significant difference; **highly significant difference; *significant difference.

Abbreviations: CCC, conventional cementum composite; CCGIC, conventional cementum glass ionomer cement; LCC, laser cementum composite; LCGIC, Laser cementum glass ionomer cement; LCCGIC, laser conventional cementum glass ionomer cement; LCCC, laser conventional cementum composite. 


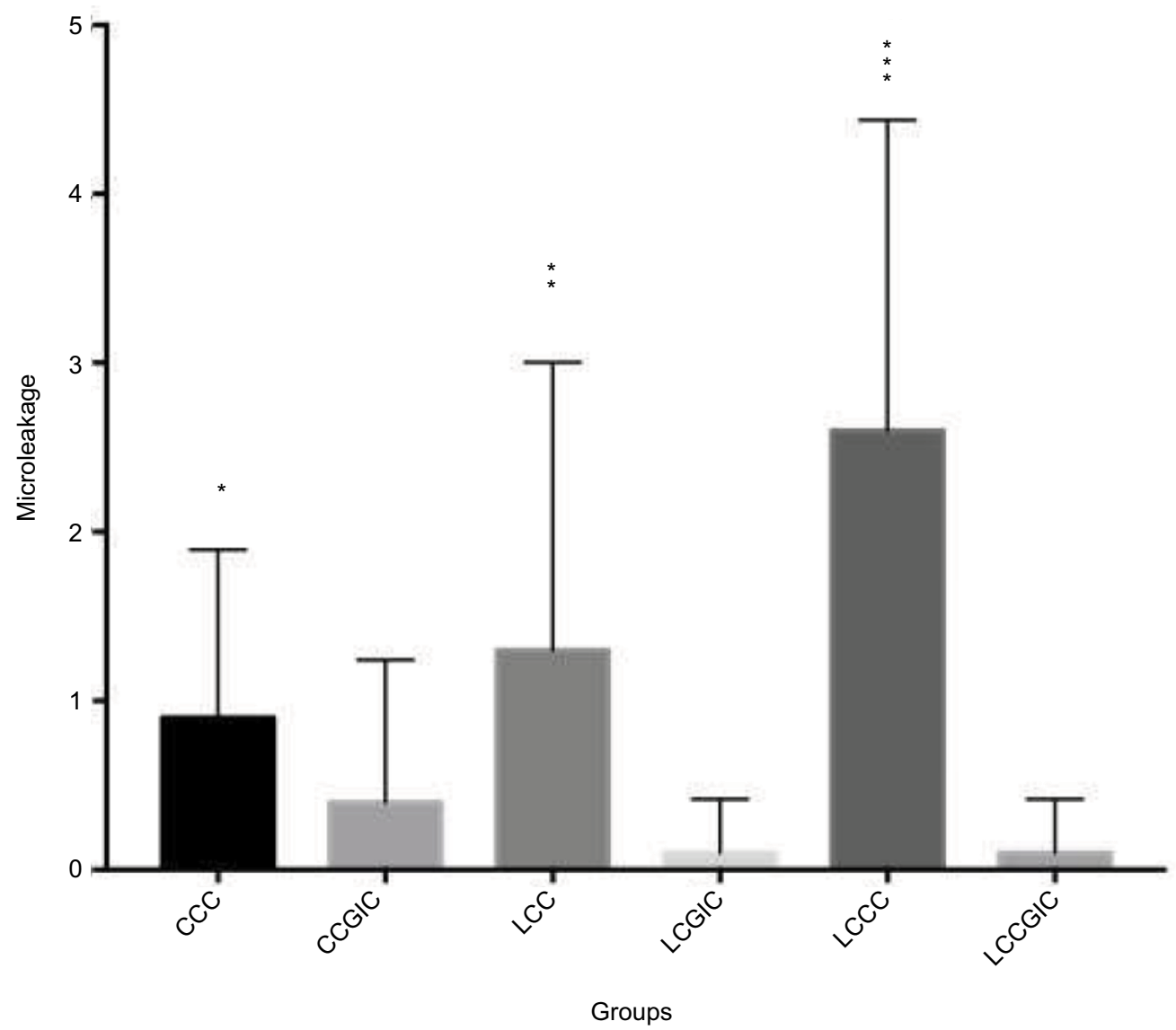

Figure 5 Cervical margin microleakage between different groups.

Note: ***Very highly significant difference; **highly significant difference; *significant difference. There was a significant difference between CCC, LCC, LCCC and the other groups in terms of microleakage.

Abbreviations: CCC, conventional cementum composite; CCGIC, conventional cementum glass ionomer cement; LCC, laser cementum composite; LCGIC, laser cementum glass ionomer cement; LCCGIC, laser conventional cementum glass ionomer cement; LCCC, laser conventional cementum composite.

\section{Discussion}

Several studies reported that the use of different adhesive systems in cavities prepared by Er:YAG laser and, regardless of the material used, showed higher microleakage in cervical margins which were located on cementum and dentine in comparison with the enamel margins. ${ }^{22,23}$ In our study, the same adhesive material, the same resin composite, and the same GI cement were used in order to determine the leakage in class $\mathrm{V}$ cavities. The apical margins of class $\mathrm{V}$ cavities were located in cementum, while the occlusal walls were located in enamel. In cementum, the results of our study showed that the composite material groups especially LCCC group have a mean microleakage value greater than the GI cement. At the gingival margin of the GI cement groups, cavities treated with polyacrylic acid revealed more leakage compared with conditioned laser-etched cavities. However, additional acid conditioning with laser etching treatment did not fulfill the amount of microleakage.

These higher composite microleakage values seen in cervical margins may be related to the lower ability of hybrid layer formation on cementum and is also related to technique sensitivity of bonding to dentine in comparison with its bonding to enamel. ${ }^{23}$ The lack of dentinal tubules and higher organic content of the dentine in cervical margins could result in higher leakages. ${ }^{24}$ GI cements especially resin-modified GIs are the material of choice when dealing with root caries or non-carious cervical lesions..$^{25}$ The results of this study are in agreement with those of other studies..$^{26,27}$

In this study, enamel, dentin, and cementum specimens were obtained from the same tooth for more standardization of the chemical composition and the degree of mineralization when the two materials were compared with each other. Laser-etching as an option for cavity conditioning prior to resin composite adhesion was investigated in a limited number of studies. It has been described that bonding to dentine is more technique- and substrate-sensitive than bonding to enamel. $^{28}$

For minimally invasive dentistry with an Er:YAG laser, a power of 10-12 W seems to be sufficient. There is no real need for the development of more powerful Er:YAG lasers, 


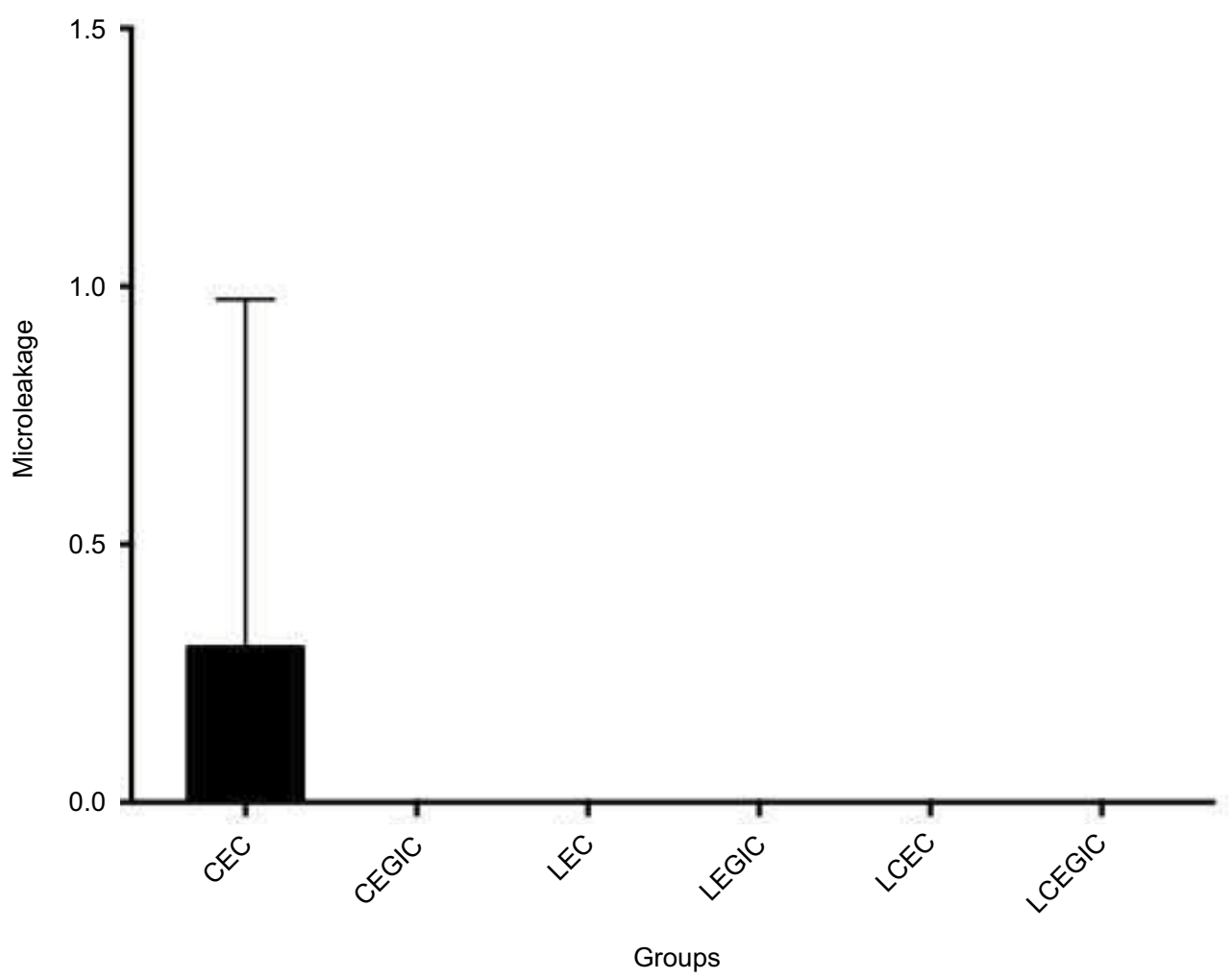

Figure 6 Occlusal margin microleakage between different groups.

Notes: There was no significant difference between groups. Nevertheless, CEC group presented more microleakage values.

Abbreviations: CEC, conventional enamel composite; CEGIC, conventional enamel glass ionomer cement; LEC, laser enamel composite; LEGIC, laser enamel glass ionomer cement; LCEC, laser conventional enamel composite; LCEGIC, laser conventional enamel glass ionomer cement.

Table 4 Grading of dye penetration of pit-fissure sealants

\begin{tabular}{lll}
\hline CS* $^{*}$ & LS & CLS \\
\hline 0 & 0 & 0 \\
0 & 0 & 0 \\
2 & 0 & 0 \\
0 & 0 & 0 \\
1 & 0 & 0 \\
0 & 0 & 0 \\
1 & 0 & 0 \\
0 & 0 & 0 \\
1 & 0 & 0 \\
0 & 0 & 0 \\
\hline
\end{tabular}

Note: *Significant difference.

Abbreviations: CS, conventional sealant; LS, laser-etched sealant; CLS, conventional laser-etched sealant.

because while speeding up the treatment by increasing pulse energy, more side effects such as leaflets and cracks may appear. ${ }^{29}$ Unlike acid etching, the mechanism of tissue removal by laser is not demineralization. A micro-ablative process causes vaporization of water and dental organic components, promoting micro explosions that cause the resulting destruction of inorganic substances resulting in microscopic surface irregularities in which the adhesive system can penetrate, fostering retention. ${ }^{30,31}$ In our study,
CEC group showed more leakage compared to LEC and LCEC, but there was no significant difference in evaluating microleakage degree. These results may be attributed to the absence of debris, as laser produces no enamel smear layer or alteration in enamel morphology. ${ }^{31}$

In comparison with acid etching, laser etching is less technique-sensitive and gives more control over the area that needs to be precisely etched. GI cement, due to properties such as adhesion to tooth structure, fluoride release, low shrinkage, low secondary caries, and low microleakage, has been widely used as restorative material. Most studies have shown a lower microleakage by resin-modified GIs than conventional GIs. In the present study, a resin-modified GI (Fuji II LC) was used as restorative material in class V cavities. Several studies have shown that resin-modified GIs showed less leakage compared with conventional GIs. ${ }^{32,33}$ Our results showed that Fuji II LC exhibited least dye penetration at both the gingival and occlusal margins.

Fissure sealing has been recognized as very effective in preventing dental decay. The long-term retention of the sealant bonding and its tight micromechanical adhesion to the enamel are dependent upon the forces of the mechanical interlocking between the resin tags, the enamel, and 


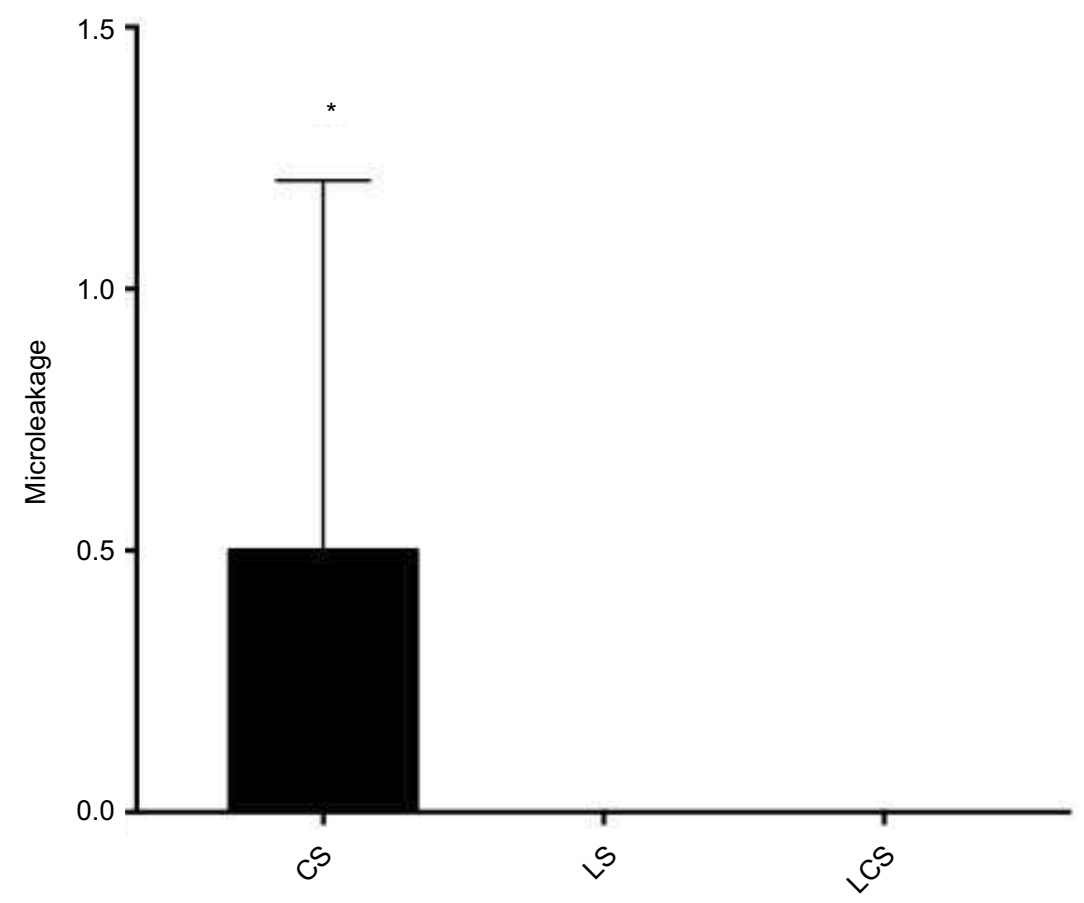

Figure 7 Sealant groups.

Notes: *Significant difference. There was a significant difference between CS and LS, LCS in terms of microleakage.

Abbreviations: CS, conventional sealant; LS, laser sealant; LCS, laser conventional sealant.

the stresses appearing at the interface. ${ }^{34}$ Sealant retention is mainly mechanical, as the physicochemical interaction between the resin and etched enamel is small.

The results of our study showed that when Er:YAG laser was used to prepare pits and fissures, it improved sealing between sealant material and enamel, but there was no significant difference between the sealant groups. The potential benefit of laser to increase the adhesion or to be used for etching tooth surfaces is still controversial. To date, the results of the studies carried out on microleakage in both class $\mathrm{V}$ cavities and fissure sealants were contradictory. ${ }^{35-37}$ The varying and conflicting results can be explained by noting that the studies were performed in different procedures and without standardization. Thus, caution is required when comparing microleakage results from different studies. Nonetheless, it is reported that microleakage tests may be reliable parameters to predict in. The operating parameters of these microleakage tests such as the number of thermocycling, dwell time, number of cycles, and dye medium were widely different. Other factors such as morphology, organic debris, and presence of aprismatic enamel could affect the performance of microleakage tests.

With the introduction of lasers in dentistry, they are indicated for a wide variety of procedures in dental practice.
The disadvantages of the dental lasers are the relatively high cost and the fact that no single wavelength is ideal for all clinical procedures.

\section{Conclusion}

Based on the results reported in this study and within the limitations of an in vitro investigation, it can be concluded that the application of the Er:YAG laser, beneath the resin composite, the resin-modified GIs, and the fissure sealant placement, may be an alternative enamel and dentin etching method to acid etching; however, further research with larger samples and a recognized consensus standard is needed. Clinical studies also need to be encouraged.

\section{Acknowledgments}

The authors wish to thank High Tech Laser Benelux especially Mr Geert De Campeneere for the valuable comments and for providing Fotona Er:YAG laser used in this study. The authors wish to thank Mr Daniel Monteyne for his contribution and technical assistance in specimen preparation and electron microscopy.

\section{Disclosure}

The authors report no conflicts of interest in this work. 


\section{References}

1. Kidd EA. Microleakage: a review. J Dent. 1976;4:199-206.

2. Buonocore MG. A simple method of increasing the adhesion of acrylic filling materials to enamel surfaces. J Dent Res. 1995;34:849-853.

3. Fusayama T, Nakamura M, Kurosaki N, Iwaku M. Non-pressure adhesion of a new adhesive restorative resin. J Dent Res. 1979;58:1364-1370.

4. Van Meerbeek B, Inokoshi S, Braem M, Lambrechts P, Vanherle G. Morphological aspects of the resin-dentin interdiffusion zone with different dentin adhesive systems. J Dent Res. 1992;71:1530-1540.

5. Nakabayashi N, Kojima K, Masuhara E. The promotion of adhesion by the infiltration of monomers into tooth substrates. J Biomed Mater Res. 1982;16:265-273.

6. Fornaini C. Er:YAG and adhesion in conservative dentistry: clinical overview. Laser Ther. 2013;22:31-35.

7. Kim Y, Hirano S, Hirasawa T. Physical properties of resin-modified glass-ionomers. Dent Mater J. 1998;17:68-76.

8. Glasspoole EA, Erickson RL, Davidson CL. Effect of surface treatments on the bond strength of glass ionomers to enamel. Dent Mater. 2002; 18:454-462.

9. Deliperi S, Bardwell DN. An alternative method to reduce polymerization shrinkage in direct posterior composite restorations. J Am Dent Assoc. 2002;133:1387-1398.

10. Gooch BF, Griffin SO, Gray SK, et al. Preventing dental caries through school-based sealant programs: updated recommendations and reviews of evidence. J Am Dent Assoc. 2009;140:1356-1365.

11. Silverstone LM. The current status of fissure sealants. Dent Pract. 1971;3:1-2.

12. Khogli AE, Cauwels R, Vercruysse C, Verbeeck R, Martens L. Microleakage and penetration of a hydrophilic sealant and a conventional resin-based sealant as a function of preparation techniques: a laboratory study. Int J Paediatr Dent. 2013;23:13-22.

13. Kuşgöz A, Tüzüner T, Ülker M, Kemer B, Saray O. Conversion degree, microhardness, microleakage and fluoride release of different fissure sealants. J Mech Behav Biomed Mater. 2010;3:594-599.

14. Eliades A, Birpou E, Eliades T, Eliades G. Self-adhesive restoratives as pit and fissure sealants: a comparative study. Dent Mater. 2013;29:752-762.

15. Hibst R, Keller U. Experimental studies of the application of the Er:YAG laser on dental hard substances: I. measurement of the ablation rate. Lasers Surg Med. 1989;9:338-344.

16. Keller U, Hibst R. Effects of Er:YAG laser in caries treatment: a clinical pilot study. Lasers Surg Med. 1997;20:32-38.

17. Mercer CE, Anderson P, Davis GR. Sequential 3D X-ray microtomographic measurement of enamel and dentin ablation by an Er:YAG laser. Br Dent J. 2003;194:99-104.

18. Schwarz F, Arweiler N, Georg T, Reich E. Desensitizing effects of an Er:YAG laser on hypersensitive dentin. $J$ Clin Periodontol. 2002;29:211-215.

19. Schwarz F, Sculean A, Berakdar M, Georg T, Reich E, Becker J. Periodontal treatment with an Er:YAG laser or scaling and root planning. A 2-year follow-up split-mouth study. J Periodontol. 2003;30:26-34.

20. Romanos G. Current concepts in the use of lasers in periodontal and implant dentistry. J Indian Soc Periodontal. 2015;19:490-494.
21. Parker S. Introduction, history of lasers and laser light production. $\mathrm{Br}$ Dent J. 2007;1:21-31.

22. Palma Dibb RG, Milori Corona SA, Borsatto MC, Ferreira KC, Pereira Ramos R, Djalma Pecora J. Assessing microleakage on class V composite resin restorations after Er:YAG laser preparation varying the adhesive systems. J Clin Laser Med Surg. 2002;20:129-133.

23. Ceballos L, Osorio R, Toledano M, Marshall GW. Microleakage of composite restorations after vacid or Er-YAG laser cavity treatments. Dent Mater. 2001;17:340-346.

24. Cagidiaco MC, Ferrari M, Vichi A, Davidson CL. Mapping of tubule and intertubule surface areas available for bonding in class $\mathrm{V}$ and in class II preparations. J Dent. 1997;25:379-389.

25. Davidson CL. Advances in glass-ionomer cements. J Appl Oral Sci. 2006;14:3-9.

26. Baghalian A, Nakhjavani YB, Hooshmand T, Motahhary P, Bahramian H. Microleakage of Er:YAG laser and dental bur prepared cavities in primary teeth restored with different adhesive restorative materials. Lasers Med Sci. 2013;28:1453-1460.

27. Delmé KI, Deman PJ, De Bruyne MA, De Moor RJ. Microleakage of four different restorative glass ionomer formulations in class $\mathrm{V}$ cavities: Er:YAG laser versus conventional preparation. Photomed Laser Surg. 2008;26:541-549.

28. Van Meerbeek B, Vargas M, Inoue S, Vanherle G. Adhesives and cements to promote preservation dentistry. Oper Dent. 2001;26:119-144.

29. Bader C, Krejci I. Indications and limitations of Er:YAG laser applications in dentistry. Am J Dent. 2006;19:178-186.

30. Shahabi S, Bagheri HG, Ramazani K. Tensile bond strength of sealants following Er:YAG laser etching compared to acid etching in permanent teeth. Lasers Med Sci. 2012;27:371-375.

31. Sasaki LH, Lobo PD, Moriyama Y, Watanabe IS, Villaverde AB, Tanaka CS. Tensile bond strength and SEM analysis of enamel etched with Er:YAG laser and phosphoric acid: a comparative study in vitro. Braz Dent J. 2008;19:57-61.

32. Toledano M, Osorio E, Osorio R, García-Godoy F. Microleakage of class $\mathrm{V}$ resin-modified glass ionomer and compomer restorations. J Prosthet Dent. 1999;81:610-615.

33. Pontes DG, Guedes-Neto MV, Cabral MF, Cohen-Carneiro F. Microleakage evaluation of class $\mathrm{V}$ restorations with conventional and resin-modified glass ionomer cements. Oral Health Dent Manag. 2014;13:642-646.

34. Silverstone LM. Fissure sealants: the enamel-resin interface. J Public Health Dent. 1983;43:205-215.

35. Borsatto MC, Giuntini Jde L, Contente MM, Gomes-Silva JM, Torres CP, Galo R. Self-etch bonding agent beneath sealant: bond strength for laser-irradiated enamel. Eur J Dent. 2013;7:289-295.

36. Marotti J, Geraldo-Martins VR, Bello-Silva MS, de Paula Eduardo C, Apel C, Gutknecht N. Influence of etching with erbium, chromium: yttrium scandium-gallium-garnet laser on microleakage of class V restoration. Lasers Med Sci. 2010;25:325-329.

37. Bahrami B, Askari N, Tielemans M, Heysselaer D, Lamard L, Peremans A. Effect of low fluency dentin conditioning on tensile bond strength of composite bonded to Er:YAG laser-prepared dentin: a preliminary study. Lasers Med Sci. 2011;26:187-191.
Clinical, Cosmetic and Investigational Dentistry

Publish your work in this journal

Clinical, Cosmetic and Investigational Dentistry is an international, peer-reviewed, open access, online journal focusing on the latest clinical and experimental research in dentistry with specific emphasis on cosmetic interventions. Innovative developments in dental materials, techniques and devices that improve outcomes and patient satisfac-
Dovepress

tion and preference will be highlighted. The manuscript management system is completely online and includes a very quick and fair peerreview system, which is all easy to use. Visit http://www.dovepress. com/testimonials.php to read real quotes from published authors. 